\title{
KIND, RELIGIE EN BOEK
}

Al sou 'n agnostikus of Kommunis ook op die teendeel hoop, bestaan daar eenvoudig nie so iets soos 'n kind sonder religieuse elemente in sy samestelling nie. Hipoteties kan dus beweer word dat, omdat die kind van religie nooit heeltemal losgemaak kan word nie, dié uiters belangrike element ook in sy literatuur ' $n$ neerslag behoort te vind. Of dit inderdaad aangetref word, is egter ' $n$ ander saak. Dis nodig om eers vas te stel wát die kind se religieuse instelling behels.

Redelik algemeen word aanvaar dat ' $n$ kind opgevoed moet word tot die besef en belewing van godsdiens. Deels is dit waar; andersyds is dit egter nie so dat hy eers op 'n bepaalde ouderdom ontvanklik word vir religie nie. Mooi stel Kuypers dit: "Het kind is een religieus kind. . . zijn diepste zijn, zijn eigenlike wezen, zijn gehele bestaan (is in de grondstructuur religieus ....1) In 'n veel resenter werk beaam Johanna Klink steeds hierdie oortuiging: "Het begint toch eigenlijk bij het begin."2).

Weliswaar beleef die jong kind religie nie as iets aparts nie; dis deel van sy totale lewenservaring. Goldman onderstreep dit: "There are no definite religious sensations and perceptions, separate from the child's other sensations and perceptions" ${ }^{3}$ ) en Violet Madge wys eweneens daarop dat die jong kind alle ervarings probeer integreer: "Aeroplanes and heaven, God and shops Jesus, and baby-sitters".4). Dis hierdie definitief aanwesige maar aanvanklik nie bewus onderskeide vermoë tot religieuse ervaring wat deur opvoeding verder ontwikkel word - of wat latent kan bly. Uit sy neiging tot religie kan hy tot begrip en mettertyd tot ware geloof kom; anders as religie as sodanig ontstaan geloof dus nie vanself en is dit nie ingebore nie: "Het moet gewekt worden", ${ }^{5}$. Juis omdat die jong kind so ontvanklik is, is hy ook besonder vatbaar vir godsdiens. Omdat hy dinge in hul totalitiet beleef en omdat hy sterk gevoelens van verbondenheid en afhanklikheid het, is dit vir hom maklik en vanselfsprekend om in sy eerste jare die Goddelike te aanvaar.

Daar is bepaalde faktore onderskeibaar wat die kind se religieuse ontwikkeling ten sterkste beinvloed. Die belangrikste hiervan is sy ouers. Dis immers in die eerste plek aan sy ouers dat die kind emosioneel verbonde is - en juis die aard van die emosionele verbondenheid bepaal die kwaliteit van sy religieuse lewe. Freud meen al dat die kind se behoefte aan sy vader die kern is van religie as sodanig; die Fransman Vergote ${ }^{6}$ ) meen ook dat die beeld wat die kind van sy vader vorm, onbewus op God oorgedra word. In sy oë het die vader 
en God dieselfde almag en alwetendheid, die een is aanvanklik lis sterk te onderskei van die ander nie. Die gevoel van aanhanklikheid, vertroue en geborgenheid wat sy ouers hom gee, wek ook God mettertyd by hom. Of in sommige gevalle natuurlik juis die teendeel: God is 'n God wat vrees inboesem by dié kind wie se ouers hom byvoorbeeld mishandel of verwerp.

Wanneer die kind later tussen God en Christus begin onderskei, ken hy eienskappe van gesag en standvastigheid veral aan God toe, terwyl die simpatie en teerheid van sy moeder oorgedra word op die Christusfiguur. Vanselfsprekend sal 'n kind dit moeilik of selfs onmoontlik vind om 'n positiewe Godsbeeld te vorm as die verhouding met sy ouers baie swak is.

Ondersoeke bring sielkundiges tot die gevolgtrekking dat seuns God anders beleef as dogters. Vir 'n seun is God 'n strenger Wese: hy sien hom as Wil, Wet en Gebod - daarteenoor is hy in baie gevalle vir die dogter sagter: veel eerder die Nuwe Testamentiese God van Liefde. Dit is moontlik die gevolg van die sg. Oedipus-fase: die seun, wat hom sterk met sy vader identifiseer, is gevoeliger vir sy eise en ervaar ook sterker skuldgevoelens vanweë sy liefde vir sy moeder. Die dogter, wat gedurende dié fase 'verlief' is op haar pa, sien hom nooit as konkurrent nie en selfs later in haar lewe bly sy op minder verwikkelde wyse geheg aan hom.

Erens tussen die sesde en agste jaar ervaar die kind die ontnugtering dat sy ouers nie werklik so almagtig en onfeilbaar is soos hy gemeen het nie. Dié besef lei tot 'n meer bewuste onderskeid tussen God en sy ouers; geleidelik verskuif sy aanhanklikheid van laasgenoemde na eersgenoemde en só ontstaan 'n verdiepte religieuse begrip en 'n universeler Godsbeeld wat nie meer so direk afhanklik is van die verhouding met die ouers nie.

Nog 'n faktor wat die kind religieus onderskraag, is sy drang tot nabootsing. Hy volg sy ouers, en mettertyd ook ander persone, na in rituele gebare soos hande vou of kniel, hy sluit sy oë vir die tafelgebed, neem moontlik deel aan huisgodsdiens, gaan saam kerk toe en sing daar saam. Aanvanklik is dié soort nabootsing ontdaan van enige diepte, hoewel dit met 'n gevoel van piëteit mag gepaard'gaan. Tog mag dit mettertyd die basis vorm van ware religieuse gevoel.

Godsdiensonderrig kan ook genoem word. Dit sal natuurlik die kind se Bybelkennis vermeerder en religieuse begrippe vir hom duideliker verstaanbaar maak. Nie sonder rede nie waarsku Klink egter daarteen dat die blote ken van Bybelgeskiedenis geen kind sal help om werklik religieus te ontwikkel nie. Van veel groter belang as meganiese feite- 
kennis is die aanleer van die regte gesindhede en die absorbeer van atmosfeer, byvoorbeeld wanneer daar uit die Bybel gelees word en tydens 'n erediens. Dit kan selfs gebeur dat die kind wat baie vroeg al gedwing word om die Bybelverhale omtrent uit die kop te ken (vóór hy dus verdiepte insig daarin kan hê) later nie meer genoeg belangstelling sal hê om betekenisse en verbande te probeer begryp nie. Die oorbekendheid van die uiterlike geskiedenisse mag hom weerhou om die onbekendheid van dit wat daaragter lê, later na te speur.

Afkeurenswaardig is die negatiewe soort godsdiensonderrig waarin so maklik verval word, met die hoofklem op straf wat sonde meebring. Dit kan lei tot wat Klink noem 'n "angstreligie." Daardeur word die kind weggeskrik van godsdiens, en word hy heeltemal onontvaklik vir die werklike evangelie.

'n Woord moet gesê word oor die kind se ingebore sin vir die mistieke, wat so nou verband hou met sy religieuse instelling. Dit lyk asof dié ontvaklikheid by hom aanwesig is afgesien van die bewuste en onbewuste godsdienstige invloede waaraan hy blootgestel mag wees. In die vorige eeu al sê Schleiermacher dat die kind blykbaar ' $n$ diep behoefte het aan die belewing van die mistieke: "However many earthly objects are presented for their knowing, there still seems to be another sense unnourished. This is the first stirrings of religion ${ }^{7}{ }^{7}$. Uit dié ontvaklikheid vir die wonder ontspring ervarings wat aan aanbidding grens. Madge glo ook dat kinders "may ... possess more of the true essence of worship than the usual adult-directed forms .8 ) Watter kinderervaring van diep misterie spreek byvoorbeeld uit dié gediggie van N. P. van Wyk Louw:

"Nog eenmaal wil ek in die skemeraand weer op ons dorp en by ons dorpsdam staan, weer met my rek óp in die donker skiet, en luister, en al word ek seer en dof,

hoe die klein klippie ver weg in die riet

uit donker in die donker water plof.91

Hoe stel die kind hom God voor? Aanvanklik is so 'n voorstelling baie konkreet en lyk God volgens die kind dikwels soos 'n ou man met ' $n$ baard. Maar dis die volwassene eerder as die kind self wat skuld het aan hierdie geykte voorstelling: dis die volwassene wat sedert die einde van die Middeleeue menslike voorstellings van God gemaak het in tekeninge en skilderye. Daarby is hy nog vir die kind geinfantiliseer sodat in baie moderne Kinderbybels God nie juis te onderskei is van mense nie - behalwe "dat dit mensenpop- 
petje in een wolk wordt getekend."10). Dit hang in alle gevalle direk van uiterlike invloede af presies hóe die kind God in sy verbeelding sal sien (al is dié invloede dikwels heeltemal onbewus of toevallig.) $\mathrm{Hy}$ is 'n wyse persoon vir wie Palestynse - of minsiens - vreemde klere aangetrek word, of Hy kan soos die eie vader lyk ... juis om Sy wysheid visueel te beklemtoon, kry Hy gewoonlik 'n baard en sien die kind hom as oud: verstand en almag word deur hom met ouder- dom geassosieer.

Hierby eindig dit gelukkig egter nie. Goldman merk op: "Children do appear to have a real sense of the omnipresence of God:"11). Aanvanklik is God en gewete vir die kind nou verwant: as hy iets verkeerds doen, glo hy geredelik dat God hom sien - dat Hy byvoorbeeld êrens agter hom staan. As hy ouer word, wen hy hom langsaam aan die idee dat God nie op konkrete wyse alomteenwoordig is nie.

Ná die skeiding tussen God en sy ouers vir die kind voltek is, kom hy tot 'n al beter omlynde konsepsie van Sy ware wese. 'n Ruk sal hy Hom moontlik nog beskou as baie oud, of hy sal nog ander menslike eienskappe aan Hom bly toeken, maar soos sy vermoë tot abstrahering toeneem begin sy konsepsie meer op geloof berus. Teen die twaalfde jaar sal hy God nie meer probeer visualiseer nie.

Naas konkrete voorstellings van God sien die kind hom vroeg in sy lewe ook al as vreemd, anders, nie-alledaags. Hy assosieer Hom byvoorbeeld met ' $n$ vreemde natuurverskynsel, 'n geheimsinnige woord, 'n naam uit die verte. Hier kom die mistieke aanvoeling weer ter sprake. Treffend word dié soort voorstelling geillustreer deur die opmerking van 'n kind nadat hy deur die mis in 'n bos gestap het: 'Ik ben door God gelopen" ${ }^{12}$ ).

Christus word aanvanklik nie van God geskei in die kind se gedagtewêreld nie omdat die twee name dikwels alternerend gebruik word. Die Christuskind wat op aarde geleef het, beskou hy as volmaak - in alle opsigte 'n Wonderseuntjie wat hom met ontsag vervul. Die volwasse Christus was 'n goeie mens - soos alle grootmense goed is. Teen agt/nege kom daar 'n skeiding tussen hierdie twee begrippe: God word met heilige respek bejeën terwyl Christus sterk geaasosieer word met Sy wonderwerke en Sy hulpvaardigheid op aarde. Die insig in Sy geroepenheid en die verband tussen Vader en Seun ontwikkel langsaam; eers teen die twaalfde jaar of selfs later begin hy dit begryp. 
Wat elke faset van sy bestaan betref, ontwikkel die kind deur bepaalde stadia. Die religie is geen uitsondering nie. Jean Piaget en ook Rümke ${ }^{13}$ ) onderskei vir stadia. Aanvanklik, in die antropomorfiese stadium wat tot die vyfde jaar duur, sien die kind God hoofsaaklik as konkreet. Hy vermenslik God om by sy sintuiglike voorstellingswêreld te pas en ken ook nie die skroom teenoor religieuse dinge wat 'n volwassene ervaar nie.

In die animisties-magiese fase glo die kind dat daar 'n samehang tussen alle dinge is en dat die verhouding tussen die natuurgegewens afhang van sy eie wil of van dié van sy ouers. As hy begin besef dat dit nie só werk nie, beroep die godsdienstig opgevoede kind hom op God: Hý veroorsaak alles. Hy is dus 'n soort towenaar in die kind se oë. In hierdie stadium is die kind wyd oop vir die wonder - waarby nie die sin vir die mistieke bedoel word waarop hierbo gewys is nie maar eerder wonder in die sin van verbeelding en die sprokiesagtige. Nou hou hy van verhale oor die skepping, God en engele, hel en duiwel, en ervaar dit as lieflike én verskriklike realiteite.

Ná die agste jaar, gedurende die intellektueel-rasionalistiese stadium, onderskei die kind skerp tussen die wêreld van die syn en die skyn. Hoewel die bonatuurlike hom nog aantrek en hy gevoelig bly vir die mistieke, eis hy meer natuurwetenskaplike verklaring vir verskynsels. Stadigaan begin hy simboliese handelinge in die godsdiens begryp, en hy leer die ambivalensie van vrees én vir die heilige aanvaar.

In die individualistiese stadium wat op elf/twaalf begin en die adolessente jare insluit, sal die kind se godsdiensbelewing volgens sy aanleg óf meer intellektueel óf meer emosioneel wees. In elk geval is sy religieuse 'beskikbaarheid' nou op sy hoogste.

Hierdie stadia gee ' $n$ aanduiding van die verloop van die religieuse gerigtheid; as finale indeling kan dit egter nie beskou word nie. Op elke vlak het die bepaalde kind se intelligensie, ervaringsmoontlikhede en opvoeding sowel as sy persoonlikheid ' $n$ woordjie mee te spreek. Skerp skeibaar sal die stadia ook nie noodwendig wees nie: die een fase kan byna ongemerk in die volgende oorgaan, of stadia kan mekaar oorvleuel.

Die rol wat gebed speel, is belangrik in die religieuse belewenis en groei. Die kind, net soos die volwassene, het behoefte aan gebed omdat hy daardeur met die Goddelike kommunikeer - en hy wil naby die Goddelike probeer kom omdat hy in iets hoër as hyself geborgenheid probeer vind.

'n Rede wat gegee word vir die mens se intuitiewe soeke na 'n hoër Wese, vir sy verlange na ' $n$ God is dat hy by sy geboorte uit die 
veiligheid in die onbekende ruimte tree - en "vanaf dat ogenblik blijft hij zoeken geborgenheid, warmte, veiligheid, misschien wel een leven lang,"14). Of hierdie teorie nou ook aanvaar word of nie: feit bly dat die behoefte bestaan, en dat dit die mens laat bid.

'n Klein kind bid naïef maar met groot erns en byna aandoenlike geloof. Dis vir hom moontlik omdat hy 'n pril aanvaarding het van God se nabyheid, en veral in sy animisties-magiese stadium, omdat hy gebed as 'n soort towerformule mag beskou wat direk beant. woord sál word. Bly die antwoord uit, beredeneer hy die feit op morele wyse: hy het nie mooi genoeg gevra nie, hy was nie soet genoeg nie, hy word so vir 'n stoutigheid gestraf. Wanneer hy bid, bid hy vir 'n Persoon wat aanwesig is of deur 'n konkrete sisteem vanuit die Hemel met hom in verbinding is.

Goldman se navorsing lei hom tot die gevolgtrekking dat die jong kind sy gebede hoofsaaklik tot God rig. Wat kinders hier te lande betref, moet die stelling egter bevraagteken word. Selfs al onderskei die kind aanvanklik nie duidelik tussen God en Christus nie, word hy gewoonlik geleer om tot 'Liewe Jesus' te bid en wek dié benaming waarskynlik by hom 'n simpatieker beeld as die meer formidabele aanspreekvorm 'God'.

Formele gebede beteken vir die kind min: hy verkies spontane gebedjies van sy eie en vind dikwels 'n groot bevrediging daarin. Hy hou daarvan om dank uit te spreek maar nog veel meer hou hy daarvan om te vra. Aanvanklik is hy wat laasgenoemde betref baie egosentries: selfs as hy vir ander bid, het dit in werklikheid betrekking op homself (byvoorbeeld dat sy ma moet gesond word sodat sy weer vir hom kan sorg). Hy vra graag stoflike dinge en sal nie om vergiffenis bid nie omdat hy dié begrip nog glad nie bemeester nie. Om dieselfde rede sal hy nie sonde bely nie tensy dit so aan hom voorgesê word - en dan beteken dit vanselfsprekend vir hom niks.

Geleidelik word sy gebede meer altruïsties en as hy teen nege/tien vir homself bid, val die klem op selfverbetering. Vanweë sy al groter besef van gevaar, sal hy ook toenemd bid om daarteen beskerm te word; ook vir siekes sal hy bid. Die konsepsie van God as 'n towenaar verdwyn in die meeste gevalle en soos hy intellektueel en emosioneel verder ontwikkel, word hy in sy gebede al meer sensitief vir sy eie (later ook ander se) dieper, onstoflike nood. Van skuld word hy bewus en hy sal vra om daarvan onthef te word.

Daar lê 'n lang ontwikkelingsperiode (wat die hele mens insluit) tussen 'n naïewe kinderdankgebedjie soos dié in Alba Bouwer se KATRIENTJIE VAN KEERWEDER, naamlik "Liewe Jesus, baie 
dankie vir die reën, amen" en die volwasse Dias se diepdeurvoelde dankbaarheid omdat, soos van Wyk Louw hom laat sê, "U tot op die naaste onvervul/en onvoltooid gelaat het, God, dié hart/ wat ek wou vul"15).

Aan die begin is die stelling gemaak dat religie, soos die kind dit as deel van sy wese ervaar, teruggevind behoort te word in sy boeke. Veral by die tekening van 'n kinderkarakter behoort 'n skrywer tog (minstens in sommige gevalle) bewustheid te toon van religieuse trekke by die karaktertjie nét soos hy bedag sal wees op uiterlike besonderhede, emosies wat hy openbaar en dies meer. Veral in Afrikaans, die taal van 'n volk wat baie lank diep godsdienstig was, verwag 'n mens so ' $n$ bewustheid. Aan hierdie verwagting word deels voldoen; grotendeels egter tog ook nié.

Die Afrikaanse kinderboek kry sy beslag in die twintigerjare. M E R se werkie KINDERS VAN DIE VOORTREK wat in 1920 verskyn, en wat in 1969 herdruk word onder die titel DIE TWEELING TREK SAAM, geld as eerste verdienstelike kinderboek. Suiwer kinderliteratuur is dit egter nog nie: die skryfster is meer daarin geinteresseerd om 'n fyn weergawe te gee van die klein alledaagse doen en dink van die Trekkers as om vanuit kinderperspektief 'n wêreld uit te beeld. Die tweeling, Gert en Mina, wat as hoofkarakters moet optree, word soms oorstem deur ander karakters en staan nie suiwer in die middelpunt van gebeure nie. Daarom vind 'n mens dat Mina wel een keer blyke gee van religieuse gevoeligheid as sy vir haar ouer suster Martjie vra: "Martjie, hoe dors 'n mens se siel na die Here?" (p. 37), maar dat dit dan eerder gaan om die beligting van Martjie se gelowigheid. Plek-plek dwing Martjie as 'n martelaarsfiguur in die boek om oor te neem as hoofpersoon. Haar innige verlange na die Hiernamaals en haar sterwensbereidheid herinner sterk aan dié van Jefta se dogter in Vondel se bekende drama oor dié Bybelse rigter. Omdat sy egter ' $n$ meisie van sewentien is, word dit nie 'n weergawe van religieuse gevoel by ' $n$ kind nie. Wat origens wel mooi is, is die verwysing na Mina se rusteloosheid wanneer daar godsdiens gehou word. Terwyl oom Frans "langsaam en ernstig uit die Heilige Boek" lees, sit Mina "kriewelrig" (p. 27) langs haar ma. Aan die singery doen sy lustig mee, maar as daar gelees word, dwaal haar aandag en kyk sy rond na al die mense. Met psigologiese insig raak M.E.R. hier dus aan die probleem van die uiterlike beoefening van godsdiens waarin ' $n$ kind nie geredelik 'n aanspraak vind nie.

Van geheel ander aard is Grosskopf se pretensielose kinderboek PATRYS HULLE wat in 1926 verskyn en vandag nog as kinder- 
klassieke in ons taal geld. Hier vorm ondeunde seunspret deur die loop van 'n laaste laerskooljaar die tema; dis 'n veel suiwerder en geslaagder kinderboek as die vorige. Religieuse instelling speel nie 'n rol nie; tog word daarna verwys dat Patrys 'n opregte gebed opstuur as Nettie ernstig siek is. Dit wys op die tipiese menslike neiging om hulp af te smeek as die nood hoog is. Met humor wat kenmerkend is in dié boek word ook gemeld dat die "dankgebed nie uitgebly" het toe Nettie later beter geword het nie. Binne die konteks van dié bepaalde boek met sy lighartige inslag word dus tóg ook erkenning gegee - al is dit oppervlakkig - aan die kind se bewustheid van God.

Deur die dertiger-, veertiger- en vyftigerjare word die boekemark oorstroom deur kinderboeke van swak gehalte. Naas oppervlakkige skool- en avontuurverhale tref 'n mens ook lektuur aan met 'n sterk godsdienstige inslag - 'n mens dink aan die werke van $M$ van Straten Regina Neser en Fanny Eden. Geeneen van hierdie skryfsters se boeke het dit egter ten doel om die inherente religieuse element in die kind se samestelling met eerlikheid en insig te vergestalt nie. Dit is oppervlakkige, swak tendenswerke - stories wat dikwels niks anders is nie as versuikerde preke. Omdat dit juis 'n kenmerk van die goeie kinderboek is dat hy nie opsigtelik wil leer of opvoed nie, dien hierdie lektuur geen doel nie behalwe om die kinderleser te stig (en te verveel). Dit lyk asof in dié jare deur hierdie soort boeke teruggekeer word na die sewentiende-eeuse opvatting "that childhood was a state to be corrected rather than enjoyed."16) en dat die kindersiel ook deur leesstof van verdoemenis gered moet word.

In Mikro se kinderboeke, wat veral vanaf die vyftigerjare begin verskyn, word die naiewe gebed ook soms opgehaal soos in PATRYS HULLE. In DIE SILWERPOTLOOD (1957) bid die skeel klein Justifina byvoorbeeld vir "'n potlood met 'n rubber in sy steel" ( $p$. 49 ) - 'n begeerte wat mettertyd vervul word. Soos in sy ander kinderboeke, word die karaktertjie hier egter oppervlakkig geteken en skep die byhaal van die soort gebedjie 'n sentimentele indruk. Weer gaan dit dus nie om 'n ernstige poging om die kinderkarakter op religieuse vlak tot sy reg te laat kom nie.

In POENS - DIE PENKOPJARE (W A de Klerk) en werke van P J Schoeman, byvoorbeeld DRIE JONG JAGTERS, word op simpatieke wyse melding gemaak van die negatiewe invloed wat Boekevat op die jong kind kan hê. Weer is die doel egter nie om die kind se religie beeldend na vore te bring nie: slegs aan sy ongemak en benoudheid tydens die lees van die Bybel en die lang gebed daarná word aandag gegee. 
Met die koms van die sestigerjare gaan die kinderboek - net soos die volwasseneprosa - met reusespronge vooruit. Tog bly dit nog eerder uitsondering as reël dat dan die religieuse aspek van die kinderkarakter aandag gegee word.

Die belangrikste vernuwer op die gebied van die kinderlektuur is $\mathrm{Al}$ ba Bouwer. Aanvanklik, in haar RIVIERPLAAS-bundeltjies, gee sy fyn en indringende beelding van die dogtertjie Alie sonder om haar egter te steur aan 'n religieuse instelling. As haar pa 'n slag uit die Bybel lees, gee die gelese gedeelte net aanleiding tot een van Alie se lewendige verbeeldingsvlugte en beteken dit niks méér nie. Mảar hier en daar gee die skryfster tóg deur besonder gevoelige taalgebruik uitdrukking aan 'n mistieke aanvoeling $b_{j ;}$ Alie. Dit kom die sterkste tot uiting tydens 'n buitediens wat op die plaas gehou word : Alie hoor die sang van die Bantoes en dit beindruk haar diep, sodat sy ook ná die diens nog stil is en daaraan terugdink: "sy hoor nog hoe die donker water deur die biesies spoel en die sterk stormwind deur die populierbome opstoot" (NUWE STORIES p. 109).

In KATRIENTJIE VAN KEERWEDER vind 'n mens 'n liefdevolle uitbeelding van ' $n$ jong dogtertjie. Dis besonder bevredigend dat dié kind geteken word in haar warm verhouding tot ouers en boetie en dat óók aandag gegee word aan bepaalde rites waarin Katrientjie sekuriteit vind. As sy saans bid, moet die bruin kwas in die vloerplank juis onder haar linkerknie wees, en haar ken moet op die boonste knoop van haar nagrokkie rus: dán eers sê sy haar gebedjie op. Dit wys op insig (wat vorige geslagte kinderboek skrywers nie gehad het nie) in die diepste wese van die kind wat die Goddelike met geborgenheid assosieer en wie se vertroue in 'Liewe Jesus' 'n refleksie is van haar vertroue in haar ouers. Haar gebedjies, as uiting van religieuse gevoel, is ook tipies van die jong kind. As haar ma por, sê sy die gewoontesinnetjies wat aan haar geleer is: "Liewe Jesus, ek is klein . . . Maak tog my hartjie rein, amen" ( $p$ 10), maar dit beteken niks. As sy dus die kans kry, bid sy spontaan - in haar geval nie vir haarself soos meestal by kleintjies die geval is nie, maar in spontane (en vir die leser aanvaarbare) dankbaarheid: "Liewe Jeus dankie vir 'n mooi dag, amen" ( $p$ 71).

By Bramie in STORIES VAN BERGPLAAS word die Kersvaderkrisis met begrip opgehaal. By dié gevoelige seuntjie bestaan daar op tien nog verwarring oor Bybelse waarhede en fantasie, sodat hy by die ou Kleurlingbediende duidelikheid vra? "Glo ta Warie aan Vader Krismis?" ( $p$ 71), en: "En wat van die liewe Jesus wat op die Kersfees gebore is, ta Warie? Dis darem regtig" $p$ 71). As hy met die be- 
paalde Kersfees wat dan in die boek tersprake kom, Kersvader finaal en bewustelik loslaat, gaan dit met 'n gevoel van droefheid gepaard wat fyn deur die skryfster gesuggereer word.

Vir my bly Alba Bouwer se mooiste werkie die heel klein DIRKIE VAN DRIEKUIL. Hoewel hier geen woord oor religie gerep word nie, maak die geheel die indruk van diepe eerbied vir wat lewe en word iets van die begrip van opstanding en nuwe lewe in die storietjie gelê dáárdeur dat die akkerboom in die middel van die dam sterf, maar daarná word hy met heerlikheid beklee as hy die tuiste word van talle bosluisvoëls: "Soos groot wit blomme sit die voëls al die takke van die akkerboom vol en af en toe kom een nog stadig aangevlieg en dwarrel saggies af tot op 'n kaal plek waar hy doodstil bly sit" (p 36). Hierdie ou dooi, swart boom word nou, soos Dirkie se ma dit stel, "'n lenteboom". 'n Subtieler groei-tot-begrip van lewe na die dood, en sin in die dood, kan 'n mens jou skaars voorstel.

Die kinderboek wat in die sestigerjare die direkste aandag gee aan die religieuse as wesenstrek van die kind, is SKRIK KOM HUIS TOE van Dolf van Niekerk. 'n Mens het waardering vir die eerlike poging wat die skrywer aanwend om veral die intense skuld- en sondebesef wat die ouer kind kan oorval, te vergestalt. Dat dit tog nie heeltemal slaag nie, is daaraan toe te skryf dat Van Niekerk nog te veel redeneer - die leser kry in hierdie verband nie die indruk van intuitiewe belewing deur die hoofkarakter Albert as sodanig nie. Dit geld naamlik die geloof aan 'n "sondeboom" wat in die dorpspark staan; wie dit aanraak, word in 'n soutpilaar verander. 'n Seun van twaalf sal net nie meer so 'n storie glo en hom so daardeur laat ontstel nie. 'n Verband word ook geslaan tussen dié boom en die Paradysboom ("Maar wie sê die park se sondeboom sal soos Aarm en Eva se boom lyk?" p 88); die simboliek is egter te opvallend.

Dié sensitiewe seun, wat blyke daarvan gee dat hy sy Bybel ken, wens 'n keer by implikasie dat die son vir hóm ook wil stilstaan, sodat hy betyds kan kom vir sy belangrike afspraak met die duiwe-eienaar: "in die Bybel het die son een maal stilgestaan omdat die mense tyd wou hê..." (p 33). Hy vra dit egter nie direk nie: daarvoor is hy te groot en voel hy ook te minderwaardig. Die verwysing dui op 'n bewustheid van God, al voel hy as verstote kind hom by God nie geborge nie.

Die suiwerste bydrae wat die boek lewer, is op die gebied van die kindergebed. Albert se hunkering na veiligheid en liefde vind uiting in die gebedjies wat hy tot "die Here" rig - beduidend juis tot die Here en nie tot God nie, want al is hy al twaalf is hy emosioneel uiters onryp en dit is dus gemotiveer dat hy nog steeds God en onverbiddelike vader in sy gedagtes sal assosieer. Die Here, daarenteen, sal vir Hom 
die sagtheid verteenwoordig wat hy met sy gestorwe moeder assosieer.

Vanweë sy ingekeerde geaardheid en negatiewe huislike omstandighede is dit aanvaarbaar dat Albert se gebede nog, soos dit eintlik by die veel jonger kind pas, volkome op eie behoeftes gerig is. Hy bid net vir homself of sy duiwe en maak van impulsiewe, onkonvensionele gebedjies gebruik: "Ek vra die Here om Spikkel se lewe te spaar" (p 8): "Ek vra die Here om my te help, want oom Johan is seker al om die draai" (p 32): "Ek vra die Here om my pa se stem sag te maak" ( $p$ 38): "Ek vra die Here om (Ma-Bet) ja te laat sê" (p 74). Dankbaarheid kom darem ook 'n keer ter sprake wanneer 'n eiertjie uitgebroei het: "Ek sê dankie 'ir die Here" (p 58).

Dis treffend dat die novelle eindig met so ' $n$ dankgebedjie nadat die duif Skrik teruggekeer het. Hier is 'n subtiele verandering wat die omvang van sy vreugde (en moontlik 'n inniger kontak met Christus, uitdruk. In plaas van die indirekte "Ek sê dankie vir die Here" soos in die vorige geval, is die gebed direk: "Ek sê dankie Here dat Skrik gekom het" ( $\mathrm{p}$ 106).

Die jonger Afrikaanse kinderboeke gee dus blyke van groter bewustheid van die religieuse aspek van die kind se samestelling. Veel word hierdie aspek egter nog steeds nie geëksploiteer nie - slegs hier en daar word dit deur 'n skrywer opgehaal. Die rede is moontlik 'n wegskram van enigiets wat dalk didakties sou kon wees (as oorreaksie teen die sieklike inslag van die vroeëre godsdienstige kinderboeke) of 'n gebrek aan begrip van hóé wesenlik religie wel deel is van die kind. Dit kan ook wees dat skrywers dit vermy, soos ook die dood as hoofmotief, omdat dit swaarwigtigheid in die hand kan werk. Tog hét dit 'n plek in die kinderliteratuur en móét dit 'n plek hê. Juis wanneer hy kan lees van karaktertjies wat bid in nood, wat hul skuldgevoelens leer verwerk, wat oomblikke van misterie ervaar, kan hy im. mers tot 'n duideliker begrip kom van sy eie religieuse behoeftes en vermoëns. Met preek het 'n uitbeelding van hierdie dinge niks te make nie; met 'n opregte tekening van die kind as totale mens egter véél.

'n Mens hoop dat die sewentigerjare kinderboeke sal bring wat getuig van sensitiwiteit vir die feit dat die kind inderdaad kragtens sy eintlike wese religieus ingestel is.

ELSABE STEENBERG.

1) Kuypers A, DE ZIEL VAN HET KIND (4e druk) p. 112 Wageningen, Zomer en Keunings 1947.

2) Klink J L, KIND EN GELOOF (3e druk) p. 28 Ambo, Bilthoven 1970. 
3) Goldman R, RELIGIOUS THINKING FROM CHILDHOOD TO ADOLESCENE (4e druk), p. 15 London, Routledge 1968.

4) Madge, Violer, CHILDREN IN SEARCH OF MEANING, p. 93 London, SCM Press 1965.

5) Klink, op cit, p 27.

6) Vergote A, THE RELIGIOUS MAN (Oorspr PSYCHOLOGIE RELIGIEUSE), Ohio, Pflaum 1969.

7) Schleiermacher F E D, DISCOURSES ON RELIGION; London 1821 p 125.

8) Madge, op cit p 94.

9) Louw N P van Wyk, Onbetitelde gedig in NUWE VERSE (2e druk), p 5 Kaapstad, Nasionale Pers 1956.

10) Klink, op cit p $10 \mathrm{G}$.

11) Goldman, op cit p 95

12) Klink, op cit, p 110.

13) Rümke H C, KARAKTER EN AANLEG I V M HET ONGELOOF. Amsterdam, Ten Have, 1939

14) Klink, op cit, p 29

15) Louw N P van Wyk, DIAS (3e druk), p 49. Kaapstad, Nasionale pers 1959.

16) Townsen J R S,SENSE OF STORY, p 201. London. Longman 1971.

AANGEHAALDE KINDERBOEKE:

Bouwer Alba.

Stories van Rivierplaas (14edruk). Kaapstad, Nasionale Pers 1970. Nuwe Stories van Rievierplaas (8e druk). Kaapsiad, Nasionale Pers 1970

Katrientjie van Keerweder (5e druk). Kaapstad, Tafelberg 1968.

Stories van Bergplaas (8e druk). Kaapstad, Tafelberg 1971.

Dirkie van Driekuil (2e druk). Kaapstad, Tafelberg 1969.

Grosskopf E B

Patrys Hulle (6e druk). Pretoria, Van Schaik 1932.

M E R

Die Tweeling Trek Saam (6e druk). Kaapstad, Tafelberg 1969.

MIKRO

Die Silwerpotlood (7e druk). Voortrekkerpers 1967.

VAN NIEKERK, DOLF

Skrik kom huis toe (3e druk). Kaapstad. Nasionale Pers 1969. 